\title{
Evolution and Regulation of Mobile Ecosystems: European Information Society Policies for the Mobile Search Domain
}

\author{
Sergio Ramos ${ }^{1}$, José Luis Gómez-Barroso ${ }^{2}$, and Claudio Feijóo ${ }^{1}$ \\ ${ }^{1}$ Universidad Politécnica de Madrid-CeDInt, Campus de Montegancedo, Spain \\ ${ }^{2}$ Universidad Nacional de Educación a Distancia, Spain \\ \{sramos, cfeijoo\}@cedint.upm.es, jlgomez@cee.uned.es
}

\begin{abstract}
After more than a decade of development work and hopes, the usage of mobile Internet has finally taken off. Now, we are witnessing the first signs of evidence what might become the explosion of mobile content and applications that will be shaping the (mobile) Internet of the future. Similar to the wired Internet, search will become very relevant for the usage of mobile Internet. Within the mobile ecosystem framework, this section will discuss if and how intense public action in the mobile search domain should (could) be. Potential actions refer both to 'conventional' and 'non-conventional' regulatory approaches. Public administrations as procurement bodies may leverage services and thus acting as early deployers of applications is an example of a 'conventional' case, while the use of the wealth of public data with high added value in mobile search scenarios would be one of a 'non-conventional' case. The section will present a list of different policy options and analyze their feasibility. These include policy options aimed both at the demand side (useroriented) and at the supply side (such as innovation-support policies, regulatory policies, industrial-type policies) of mobile search.
\end{abstract}

Keywords: mobile search, Information Society policies.

\section{Introduction}

The mobile base will reach nearly 5 billion subscribers worldwide by 2012 . By the end of 2013, broadband mobile connections will account for more than half of all connections and $40 \%$ of total subscribers are expected to adopt mobile internet. Its emergence will support an explosion of mobile content and applications. Numerous examples could be mentioned: new entertainment content produced and personalized for the mobile environment, productivity applications for mobile workers, or health and education mobile solutions to increase quality of life, since the mobile device is "the mean to harness collective intelligence at the point of inspiration".

Similarly to the wired internet, many of these new mobile web models will require access to data in an orderly and meaningful manner. Search engines, which are already gateways for more than half of the users connecting to the internet, will 
therefore become (are already becoming) the mean to reach appropriate content and applications, and to provide additional value to services in mobile platforms.

In addition, mobile search has unique features in providing added value in a number of environments. It exploits the fact that mobiles are very personal devices storing and regularly capturing data about the user, like the user's location, contact lists, preferences, etc. This enables context-aware search services in current and future ambient intelligent environments (e.g. making use of wireless sensors and cognitive techniques). In short, search is likely to become equally or even more critical in the mobile domain than in the wired environment.

As a result, mobile search is becoming an attractive expansion market for all types of existing players (web search engine providers, telecom operators, handset suppliers) and newcomers. It is a clash in many respects: different business cultures (ex-monopolists vs. start-ups), governmental influences (highly regulated vs. nonregulated), business models (subscription-based vs. advertising-based) and the relationship between user and service provider (price-based vs. innovation-based).

\section{The Mobile Search Ecosystem}

The ecosystem metaphor is useful to describe the relationship of a considerable number of players interacting amongst themselves within a given environment and in which none of players controls the system completely; thus, both collaboration and competition occur at the same time. Today's mobile ecosystem is characterized -in general terms- by an increasingly intense competition at the mobile platform level [3], [9]. With respect to previous periods, the focus of the mobile industry has shifted "from single-firm revenue generation towards multi-firm control and interface issues" [1], [2].

Other authors propose a general model for any mobile content or application [6], [7], which can be adapted also to the mobile search case. The roles of players in the mobile search value network can be broadly divided into three main stages: information processing, delivery and capture/use/interaction.

This three-layer structure is typical of ICT ecosystems [8]; it is developed in Figure 1 presenting the main activities that players can adopt. For each of the three main stages their major contributions are presented in light grey boxes. The dark grey boxes highlight activities which could be considered new to mobile search. Figure 1 includes also the different phases of the mobile search evolution (light to dark blue underlying boxes): the initial on-portal approach (left), the subsequent on-device and additional 'input functionalities' (down), the mobile version of web search (right) and, finally, the context-aware search (up).

The mobile search provision to users requires the contribution of players carrying out most of the activities shown. Obviously some of these players will try, and eventually succeed in, integrating as many activities as possible for a tighter control of the value network. This strategy will result in a "platformization" of the ecosystem, in which each player fights to shift the value towards the platform under its control, ideally including a "gatekeeper" role [4]. Existing web search engines, including the necessary adaptations to the mobile environment, are one of these platforms where the gatekeeping role is mainly related to their favorable and unique position to act as an entry point for end-users to retrieve, subscribe and use content and applications [5]. 


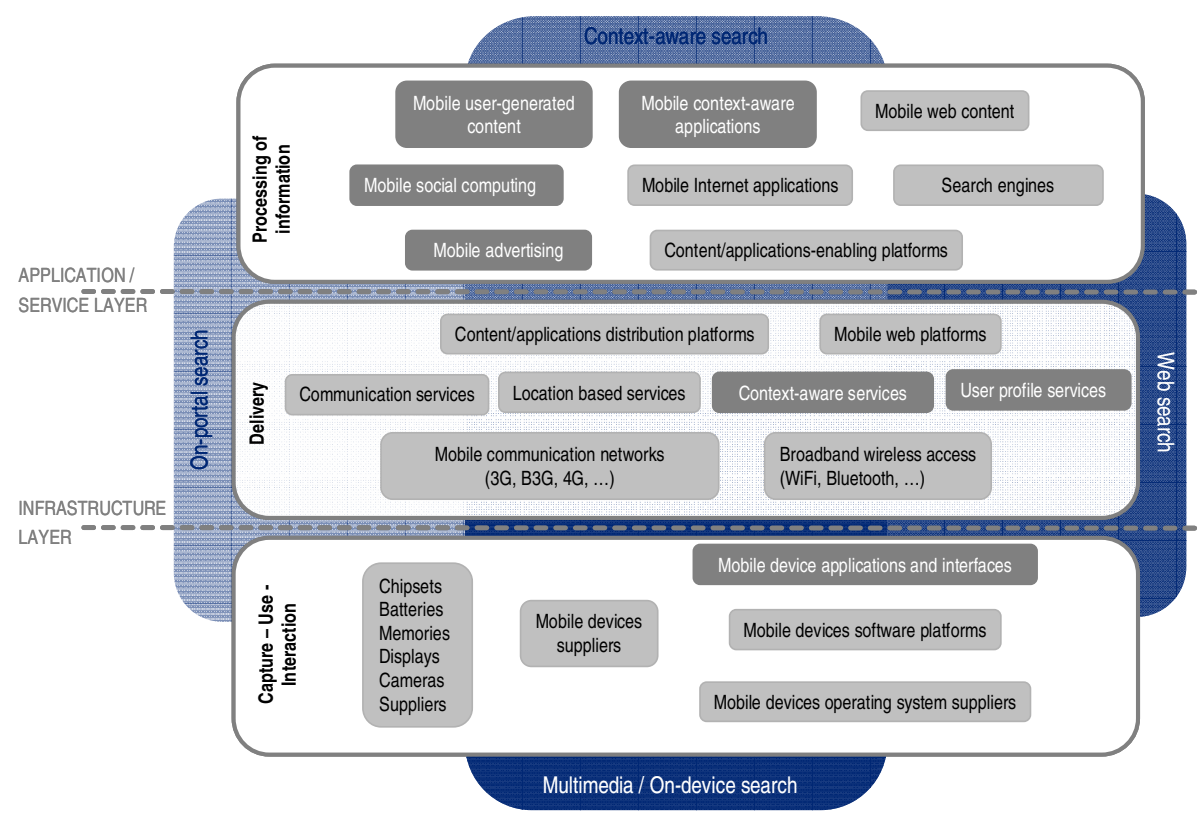

Fig. 1. Activities and players in the mobile search ecosystem [9]

\section{Technologies Driving the Evolution of Mobile Search}

From a general perspective, there are three main technology families that have a direct impact on mobile search: enabling technologies, search technologies (in general) and specific mobile search technologies, as described in Table 1.

Search technologies, for example for retrieving accurate and enriched content may include semantic approaches, cognitive approaches and multimedia retrieval. Specific mobile search technologies include technologies that render mobile data acquisition, its processing and matching of context-awareness, or that introduce augmented reality technologies to enrich context awareness. Finally, technology components that enable mobile applications include wireless networks (broadband access ubiquity, dynamic spectrum management), sensor networks (Radio Frequency Identification or RFID, Internet of Things), devices (multimedia capabilities, location, interoperability, openness), and cloud computing (web browser, connectivity, security, data protection).

Interestingly, most of these technological building blocks are either already available or in an advanced prototype stage. However, they have not yet been used to any great extent in commercial services and applications. Thus we conclude that, in the short to medium term, there is no missing "critical technological component". Instead, the main technological challenge is to better integrate (existing) technologies. In other words, system integration and technological interoperability is the key to success, rather than the development of new "hard-core" search components. 
With regard to the long-term prospects, system integration is particularly challenging, i.e. getting the necessary components operational for the next generation of mobile networks, 4G-type and beyond (arguably the most relevant enabler of mobile search). In addition, current and future networks will also be interoperable with other types of wireless networks such as near field communications for interaction with sensors.

Table 1. Technologies having direct impact on mobile search

\begin{tabular}{|c|c|c|}
\hline & Technology & Keywords \\
\hline \multirow{4}{*}{ Enabling technologies } & Wireless networks & $\begin{array}{l}\text { Broadband access ubiquity, dynamic } \\
\text { spectrum management }\end{array}$ \\
\hline & Sensor networks & RFID, internet of things \\
\hline & Devices & $\begin{array}{c}\text { Multimedia, location, interoperability, } \\
\text { openness }\end{array}$ \\
\hline & Cloud computing & $\begin{array}{c}\text { Web browser, connectivity, security, } \\
\text { data protection }\end{array}$ \\
\hline \multirow{2}{*}{$\begin{array}{l}\text { Search technologies } \\
\text { (general) }\end{array}$} & Semantic and multimedia & Enriched content search \\
\hline & Cognitive & Environment understanding \\
\hline \multirow{2}{*}{$\begin{array}{l}\text { Mobile search technologies } \\
\text { (specific) }\end{array}$} & Context awareness & Context acquisition and processing \\
\hline & Augmented reality & Enriched context awareness \\
\hline
\end{tabular}

\section{Sources of Revenues in Mobile Search}

Using the above framework and compiling revenue models from available literature on the mobile web, applications, content and service models, Table 2 summarizes, from the authors' perspective, the revenue models that mobile search providers are using or could use. They are shown from the perspective of final users, and therefore, intermediate provision models (e.g., white labels, wholesale, brokerage, billing services, software development, hosting, etc) are not considered.

The table includes an example usage scenario (later used for the experts' survey) to better indicate the level of their current existence in practice and their connection with the two main types of mobile search previously described. The fourth column in the table is an indicative of the new business models that context-awareness can bring and which are not present, in general, in the web-based type of search. The revenue models for mobile operators, hardware and software suppliers and other potential intermediaries are not shown in Table 2, although some of them could benefit indirectly from the adoption of mobile search. Finally, also note that the presented revenue schemes are not exclusive and could be complementary to each other.

This list highlights the expectations put on advertising and user profiling as main revenue models in mobile search. In the advertising model, typically the search results are provided free-of-charge to final users and the revenues are generated from thirdparty advertisers. Advertising models include several very different business strategies. For instance, there could be off-portal campaigns for certain categories of services, such as travel, restaurants, automotive, or consumer electronics. A traditional strategy consists in simply adding a banner on search results, usually 
including a direct response method as well (a link to a microsite, a click-to-call link, or a short code). This approach fits well, for instance, into events.

As another example, click-to-call text links connected to search results is a simple way to leverage the voice capabilities of mobile devices. Off-portal keyword bidding - also called auctioning-, especially for marketers offering digital content, is another main example. Without exhausting all the possible options, ad campaigns for products related to what mobile operators offer on their mobile portals (ringtones, games, wallpapers, music, video, etc) is an example of on-portal search. Each of these examples could be equally applied to the case of user profiling in exchange for providing the mobile search results.

The list also denotes the still largely unexplored potential of applications where mobile search, typically of the context-aware category, is the engine within. Mobile application providers are looking for business models to incorporate the revenue flow from the application itself, therefore departing from the traditional pay-per-download. There are different business tactics here as well. These can include time-based billing for services, event-based billing for specific situations or item-based billing as a function of the results obtained in the search.

Table 2. Main revenue models for mobile search

\begin{tabular}{lcc}
\hline \multicolumn{1}{c}{ Revenue model } & $\begin{array}{c}\text { Example of scenario } \\
\text { of usage }\end{array}$ & $\begin{array}{c}\text { Currently in } \\
\text { use in general }\end{array}$ \\
\hline $\begin{array}{l}\text { Pay-as-you-go (impulse purchase) } \\
\text { Subscription }\end{array}$ & Travel & No \\
\hline Premium services (basic functionality free) & Leisure & No \\
\hline $\begin{array}{l}\text { Value-added services (additional contract for services on } \\
\text { top of conventional ones) }\end{array}$ & Productivity & No \\
\hline Merchandising - Affiliation & Well-being & No \\
\hline Packaged with the mobile device & Consumer good & Yes \\
\hline $\begin{array}{l}\text { Packaged with the (voice, data) services of the mobile } \\
\text { operator }\end{array}$ & Information & Yes \\
\hline $\begin{array}{l}\text { Packaged with some product or service not related with } \\
\text { mobile ICTs }\end{array}$ & Content & No \\
\hline $\begin{array}{l}\text { Advertising in general } \\
\text { Advertising linked with product placement }\end{array}$ & Health \\
\hline $\begin{array}{l}\text { Exploiting user profile derived from mobile search for } \\
\text { marketing purposes }\end{array}$ & $\begin{array}{c}\text { Additional value in } \\
\text { purchase of goods }\end{array}$ & No \\
\hline Maintained by user community (and free for final users) & Marketing & Yes \\
\hline Public service (not a commercial one) & Community & Yes \\
\hline Public service (not a commercial one) & City planning services & No \\
\hline
\end{tabular}

\section{$5 \quad$ SWOT Analysis of Mobile Search}

One of the main objectives of this chapter is to analyze strengths, weaknesses, opportunities and threats (SWOT) for the future success of the mobile search domain (cf. Table 3), as a tool to be considered by European decision-makers. 
Table 3. SWOT analysis

\begin{tabular}{|c|c|}
\hline $\begin{array}{l}\text { EU Strengths } \\
\text { Extremely high penetration of mobile } \\
\text { technologies and critical mass of advanced } \\
\text { mobile users } \\
\text { Industrial landscape strong (operators, } \\
\text { suppliers...) and past success stories of co- } \\
\text { operation } \\
\text { Main technological puzzle pieces in place } \\
\text { (devices, networks, applications...) } \\
\text { - Good research standards } \\
\text { - Increasingly available and affordable mobile } \\
\text { broadband connections } \\
\text { Increasingly available, affordable and usable } \\
\text { mobile devices } \\
\text { Availability of content of higher quality for } \\
\text { mobile use (geo, land-property registry,...) } \\
\text { Availability of public funded content } \\
\text { (broadcasting...) } \\
\text { Multicultural background } \\
\text { Public awareness of privacy issues and } \\
\text { increasingly focused laws and regulation }\end{array}$ & $\begin{array}{l}\text { EU Opportunities } \\
\text { Improving the integration between web/mo- } \\
\text { bile/PC platform for a richer user experience } \\
\text { Existence of niche markets/services related to } \\
\text { mobile search } \\
\text { - Mobile search linked with local content } \\
\text { (multicultural) } \\
\text { Partner with the experiences of mobile } \\
\text { internet usage in developing countries } \\
\text { Be the first to put in place a new (regulatory) } \\
\text { framework for API's-interoperability, privacy } \\
\text { - Create an open ecosystem for data portability } \\
\text { among players and applications based on } \\
\text { mobile search } \\
\text { - Liberation of European public data for the } \\
\text { creation of new services and applications } \\
\text { - Use forthcoming disruptions (cloud } \\
\text { computing, internet of things...) } \\
\text { Empowerment of the user for granular } \\
\text { privacy and identity control internet of things } \\
\text { debate. }\end{array}$ \\
\hline $\begin{array}{l}\text { EU Weaknesses } \\
\text { Techno-economic and market fragmentation } \\
\text { (data roaming, standards, application stores, } \\
\text { convergent regulation, cultural diversity...) } \\
\text { Need for better / understandable / more } \\
\text { secure pricing models and roaming charges in } \\
\text { mobile broadband connections } \\
\text { - Lack of interoperability and (open) standards } \\
\text { Uncertain strategies for revenue generation, } \\
\text { early state of development of business model } \\
\text { Strategic decisions on innovation and invest- } \\
\text { ments in (mobile) search are outside the EU } \\
\text { - Search mostly dominated by global } \\
\text { companies } \\
\text { Lack of entrepreneurship culture and frame- } \\
\text { work for continuing venture capital action }\end{array}$ & $\begin{array}{l}\text { EU Threats } \\
\text { Delay of enabling technology developments } \\
\text { Increasingly fragmented market (silos, } \\
\text { platforms, app stores...) and closed } \\
\text { ecosystem (mobile search needs links and } \\
\text { references with other domains) } \\
\text { - Companies outside EU will control the } \\
\text { developments in mobile search } \\
\text { Asymmetry of regulation among electronic } \\
\text { communications, internet services and content } \\
\text { regimes } \\
\text { - Regulatory lag (spectrum management...) } \\
\text { Privacy and data protection issues not } \\
\text { acknowledged and solved }\end{array}$ \\
\hline
\end{tabular}

On the demand side, Europe enjoys a large base of early adopters of mobile search and a huge mass of mobile users with the economic strength to demand and pay for advanced mobile internet services that satisfy their expectations and requirements. On the supply side, Europe's industry is able to provide users with all the required technology. The industrial tissue is strong and readily available in all required sections of the mobile search ecosystem and particularly strong in some parts of it (telecommunications, handset producers and software and application providers). European companies have significant experience in past success stories (and failures) and, more important, they are increasingly pushed by the market, to simplify mobile tariffs and make them more affordable. Thus, a very positive conclusion is that Europe has both a strong supply and demand side in mobile search. Moreover, European industry is also actively involved in developing countries where mobile devices will become prime means to access the internet. This shared experience could become beneficial in both ways: spreading European innovations and learning from massive usage of mobile internet access. 
One specific European asset is that Europe possesses a large collection of high quality information that may trigger advanced mobile search applications at the service of the citizens. Geo-data (e.g., cadastre), images and pictures (e.g., national libraries), or video (e.g., public broadcasters) are examples of data collections in the hands of public authorities, which have already been digitized to a very large extent, that could add significant value to new categories of mobile search. Note that most of this content comes from public sources and/or has been subsidized in the past by public institutions. It seems that public administrations have not yet fully understood how they can exploit in the best possible way this value and how to get into various partnerships and collaborations to unlock its potential. The prospect of "liberation" of public data could also put governments into a favorable position to enforce an open and "loose interoperability" model to allow data portability across applications and players. Forthcoming disruptions in technology could help to deploy such models.

Finally, the many times used but also many times empty-of-practical application motto of "reaping the benefits of Europe's cultural diversity" could become true in the mobile search domain. Some of the most promising applications of mobile search pivot around local information, local culture and specific languages, which is supposed to be complemented by the emergence of many niche markets and services. Civil society is increasingly aware of the need to establish digital identities, which in turn sets the conditions for a stable and firm framework to develop mobile (search) applications, both appealing to users and respectful with them and their preferences and motivations. Europe could be the first to put in place such a light-handed and user-empowered regime shifting the interest of global innovators in mobile search.

Still there are many challenges and barriers to be overcome. The current mobile ecosystem is largely fragmented in terms of both techno-economic models and markets. On the techno-economic side, there are multiple layers (devices hardware and software, applications, networks, development platforms, content platforms, etc) composed of competing, closed and non-interoperable standards. On the market side, the European internal market is far from being established (think on roaming charges, for example) and recent practices (applications stores) keep the tradition of silo incompatible models. Mobile broadband connections are still expensive, particularly in many situations where mobile search would have an extreme value for users (such as finding places in foreign countries), high roaming charges dissuade users from even attempting to connect to the internet. Monetizing mobile search is also still a pending issue. Many business models are possible as discussed before, but none of them has yet crystallized as the winning one.

The mobile search market will remain to be heavily influenced by the web search engines. Given that the most influential ones have all their headquarters abroad, many of the strategic decisions that would influence the evolution of the domain are going to be taken outside Europe's frontiers. To compensate such an effect, a more supportive framework (cultural, institutional and business-like) for entrepreneurs and innovators in Europe would be needed.

The potential delay in the adoption of appropriate regulation regimes (electronic communications, spectrum management, content, consumer protection, etc) will slow the adoption of mobile search. In this sense, a stable, clear and forward-looking framework is desirable which would address the new issues coming from advanced mobile applications. 
Finally, there is a risk of a mobile digital divide. Next generation mobile infrastructures may not reach some geographical areas in the short to middle term and the prices both of devices and mobile connections are not affordable for many citizens. Also the skills and physical capabilities to use a mobile device in a search scenario need to be further addressed.

\section{Policy Options Scenarios}

Following the SWOT analysis conclusions, a list of potential policy options have been considered, grouped in relevant areas of action as shown in Table 4.

Table 4. Summary of potential policy options

\begin{tabular}{|c|c|}
\hline Potential Policy Options & Main issues \\
\hline $\begin{array}{l}\text { User-oriented policies } \\
\text { aimed at the demand side } \\
\text { of mobile search. }\end{array}$ & $\begin{array}{l}\text { Enhance user-awareness of opportunities and risks. } \\
\text { - Create (policy-push) tools for user empowerment. }\end{array}$ \\
\hline $\begin{array}{l}\text { Innovation-support } \\
\text { policies }\end{array}$ & $\begin{array}{l}\text { - Supporting innovators and entrepreneurs through an improvement of the } \\
\text { institutional framework. } \\
\text { - Promoting living labs, in particular, for mobile applications } \\
\text { - Promoting research projects focused on missing technologies }\end{array}$ \\
\hline Regulatory policies & $\begin{array}{l}\text { - Reforming the mobile search regulatory framework. } \\
\text { - } \quad \text { Promoting self-regulation of the mobile search industry. } \\
\text { - } \text { Mandate data portability suitable for mobile search applications. } \\
\text { - Creating and enforcing an independent agency. }\end{array}$ \\
\hline Industrial-type policies & $\begin{array}{l}\text { - Promoting standards and interoperability. } \\
\text { - } \quad \text { Promoting content production suitable for mobile search. } \\
\text { - Setting up a multi-stakeholder platform. } \\
\text { - Helping accelerate the deployment of 4G mobile broadband }\end{array}$ \\
\hline $\begin{array}{l}\text { Public involvement in the } \\
\text { supply side of mobile } \\
\text { search }\end{array}$ & $\begin{array}{l}\text { - Development of mobile search public services. } \\
\text { Public procurement. }\end{array}$ \\
\hline
\end{tabular}

\section{$7 \quad$ Summary and Conclusions}

The overall vision on policy is that the mobile search domain requires a combination of different types of actions to thrive and succeed. Looking in detail into each of the potential policy measures, in the first place, there is a need to impel the demand side of mobile search, raising the awareness of users and then empowering them with the tools to manage their data. This should be complemented with reinforcing all polices aimed at innovation: from the support to innovators and entrepreneurs, to the use of living labs and the more traditional research programs. On the regulation side, it is considered that the existing frameworks should be quickly reviewed and adapted to the new needs of advanced mobile applications. However, there is no much faith amongst experts in the self-regulation of the industry or in other actions beyond the regulatory framework like specific agencies or decisions. From the industrial policy perspective, the idea of promoting the use and adoption of open standards and the 
achievement of a reasonable level of interoperability, including, if needed, a platform to gather all the stakeholders involved is considered of high potential. Helping to develop content for added value mobile search is also highly regarded. Finally, it is thought that for some niche mobile search applications public administrations can have a leading role, setting the conditions for their deployment or even becoming their providers.

Open Access. This article is distributed under the terms of the Creative Commons Attribution Noncommercial License which permits any noncommercial use, distribution, and reproduction in any medium, provided the original author(s) and source are credited.

\section{References}

1. Ballon, P.: Business modelling revisited: the configuration of control and value. Info. 9(5), 6-19 (2007)

2. Ballon, P.: Changing business models for Europe's mobile industry: the impact of alternative wireless technologies. Telematics and Informatics 24(3), 192-205 (2007)

3. Ballon, P.: Control and Value in Mobile Communications: A Political Economy of the Reconfiguration of Business Models in the European Mobile Industry. Vrije Universiteit, Brussel (2009)

4. Ballon, P.: The platformisation of the European mobile industry. In: European Communications Policy Research, EuroCPR (2009)

5. Ballon, P., Walravens, N., Spedalieri, A., Venezia, C.: Towards platform business models for mobile network operators. In: 19th European Regional ITS Conference (2008)

6. Feijóo, C., Maghiros, I., Abadie, F., Gomez-Barroso, J.: Exploring a heterogeneous and fragmented digital ecosystem: mobile content. Telematics \& Informatics 26(3), 282-292 (2009)

7. Feijóo, C., Maghiros, I., Bacigalupo, M., Abadie, F., Compañó, R., Pascu, C.: Content and applications in the mobile platform: on the verge of an explosion. Institute for Prospective Technological Studies (2009)

8. Fransman, M.: The new ICT ecosystem. Implications for Europe, Edinburgh, Kokoro (2007)

9. Ramos, S., Feijóo, C., González, A., Rojo, D., Gómez-Barroso, J.: Barriers to widespread use of mobile Internet in Europe. An overview of the new regulatory framework market competition analysis. The Journal of the Communications Networks 3(3), 76-83 (2004) 